\title{
LITERATURA INFANTOJUVENIL E FORMAÇÃO DOCENTE: ATIVIDADES EXTENSIONISTAS NA INTERLIGAÇÃO ENTRE UNIVERSIDADE E COMUNIDADE
}

\section{YOUTH LITERATURE AND TEACHERS' EDUCATION: UNIVERSITY OUTREACH ACTIVITIES CONNECTING UNIVERSITY AND COMMUNITY}

\author{
Maria Isabel Alonso Alves* \\ ORCID: https://orcid.org/0000-0002-2960-1200 \\ Genivaldo Frois Scaramuzza* \\ ORCID: https://orcid.org/0000-0003-3738-9905 \\ Simone Alves Scaramuzza** \\ ORCID: https://orcid.org/0000-0002-1434-4694
}

\section{RESUMO:}

A extensão universitária possibilita a execução de atividades com interesse social e busca interligar ações desenvolvidas entre a universidade com a comunidade. A presente reflexão comunica resultados do projeto de extensão "A literatura infantojuvenil como contributo para a promoção humana no contexto municipal de Humaitá/AM". Tem como objetivo expor compreensões de extensionistas vivenciadas em espaços de contação de histórias para crianças em situação de vulnerabilidade social. As atividades desenvolvidas são ações originadas de atividades extensionistas que se enquadram em uma perspectiva qualitativa, a partir de experiências de uma práxis educativa pautada na açãoreflexão-ação. Podemos dizer que a efetivação da extensão na comunidade, relatada pelos estudantes, dá conta de que a prática formativa docente ocorre mediante accão, reflexão e intervenção pedagógica e que a parceria entre universidade/comunidade proporciona melhorias no processo de educacional.

Palavras chave: Formação docente; Extensão universitária; Práticas formativas.

\begin{abstract}
:
University outreach allows the execution of activities of social interest and seeks to link actions developed between the university and the community. This reflection communicates the results of the outreach project "Youth Literature as a Contribution to Human Promotion in the Municipal Context of Humaitá / AM". It aims to expose the participants' understandings of experiences lived in storytelling spaces for children in social vulnerability. The actions developed originated from outreach activities that fit in a qualitative perspective, from experiences of teaching based on action-reflection-action. We can say that the realization of the outreach project in the community, reported by the students, shows that the teaching formative practice occurs through action, reflection and pedagogical intervention and that the partnership between university / community promotes improvements in the educational process.
\end{abstract}

Keywords: Teachers' education; University outreach; Formative practices.

\footnotetext{
*Professora da Universidade Federal do Amazonas (UFAM), Humaitá - AM, Brasil. E-mail: mialonsoster@gmail.com

${ }^{* *}$ Professor da Universidade Federal de Rondônia (UNIR), Ji-paraná - RO. E-mail: scaramuzza1@gmail.com

*** Aluna de Doutorado da Universidade Católica Dom Bosco (UCDB), Campo Grande - MS. E-mail: simonescaramuzza23@gmail.com
} 


\section{Abordagens iniciais}

O processo de formação docente no país vem passando por significativas mudanças. Nesse aspecto, constata-se a busca pela aproximação cada vez mais consistente entre aqueles que futuramente assumirão os espaços de aprendizagens formais e os que buscam nestes espaços conhecimentos necessários à realização da vida. Neste sentido, a universidade tem construído alternativas que buscam aproximar e tornar a prática da aprendizagem e formação entrelaçada às realidades concretas, aquelas que definitivamente devem ser, se necessário, transformadas pela ação docente.

Considerando essa máxima, o texto em tela refere-se à análise de compreensões a respeito do desenvolvimento de atividades de extensão - Programa de Atividade Curricular de Extensão - PACE/PROEXTI desenvolvido no âmbito da formação docente no Curso de Pedagogia do Instituto de Educação, Agricultura e Ambiente da Universidade Federal do Amazonas - IEAA/UFAM. As ações de extensão mencionadas referem-se a atividades, sobretudo formativas, tanto do ponto de vista de quem "sofreu" a natureza das intervenções, como daqueles que, no âmbito dos espaços universitários, produziram não apenas interações sociais com a comunidade externa, mas puderam observar e colocar em prática os pressupostos pedagógicos envoltos à dinâmica do ensino-aprendizagem.

Para a composição dos dados analisados neste artigo, pautamos-nos na abordagem qualitativa de pesquisa em educação com uso da pesquisa documental, tendo os relatos de experiência dos discentes do curso de Pedagogia do Instituto de Educação, Agricultura e Ambiente IEAA/UFAM que participaram da atividade extensionista como principais colaboradores. Apoiamo-nos, também, em Ludke e André (2013), que definem a pesquisa qualitativa como subjetiva e interpretacionista, já que não tem a pretensão de influenciar no ambiente em que está se pesquisando, apenas tenta buscar respostas para os questionamentos levantados.

A respeito da abordagem qualitativa, também tivemos como base Godoy (1995), que vem explicar que esta abordagem não se apresenta como uma proposta rigidamente estruturada, mas permite que a imaginação e a criatividade levem os investigadores a propor trabalhos que explorem novos enfoques. Assim consideramos, neste estudo, como principal fonte de dados um conjunto de relatos produzidos por extensionistas da Universidade Federal do Amazonas, unidade de Humaitá (UFAM/IEAA). Podemos dizer que este movimento inerente à investigação em educação, também, possui ascendência na concepção de uma práxis educativa, um movimento contínuo que interliga dialeticamente a ação e reflexão. Compreendemos a práxis educativa como

[...] reflexão e ação dos homens sobre o mundo para transformá-lo. O embate dialético entre ação-reflexão presente neste método favorece a uma mudança da consciência humana da estrutura social e a uma aproximação crítica, reflexiva da realidade estudada (PIO et al., 2014, p. 57).

Esse mesmo pressuposto é apresentado por Freire (1987) ao dizer que a práxis impõe um movimento permanente, instância de consciência em que "o pensamento dos homens referido à realidade, é investigar seu atuar sobre a realidade, que é a sua práxis" (FREIRE, 2008, p.98).

Nossas indagações versam sobre a relação da formação docente e a extensão universitária, de modo que os dados produzidos nesta pesquisa foram efetivados a partir dos relatos de experiência dos discentes que participaram das atividades de extensão. A principal questão que motivou esta reflexão foi: Como a extensão universitária possibilita a formação de um professor capaz de refletir sobre a relação teoria e prática? Podemos inferir que formar o professor reflexivo é de necessidade urgente numa sociedade que está em constante mudança, em que profissão docente é cada dia menos valorizada, contudo, cada vez mais necessária.

A existência de professores que saibam entender as transformações ocorrentes na sociedade, com a finalidade de atuar com responsabilidade e compromisso com a educação de seus alunos é urgente. Professores que, além de ensinar, utilizem os 
problemas presentes em sua sala de aula e no espaço escolar para desenvolver pesquisas e tentar superar as dificuldades que se apresentam na educação se faz necessário na sociedade atual. Formar este professor na graduação é um grande desafio.

De acordo com André (2012), as propostas curriculares dos cursos de formação inicial no Brasil têm apresentado poucos avanços em relação a favorecer sólidos conhecimentos teórico-práticos para que o professor possa atuar também como pesquisador em sala de aula. Superar a dicotomia existente entre o professor que leciona conteúdos e o professor que, além de ensinar, transforma a sala de aula em um laboratório de pesquisa não é apenas uma possibilidade, mas também um grande desafio. Por isso, a necessidade de evidenciar este debate.

\title{
Formação docente: contextos e desafios
}

No ensino superior, desde 1930, há o princípio da indissociabilidade entre pesquisa e ensino, pelo menos na escrita oficial, a Lei de Diretrizes e Bases - LDB (1996), no artigo 43, a educação superior deve incentivar o trabalho de pesquisa e investigação científica, buscando desenvolver a ciência, a tecnologia, criação e difusão da cultura, no entanto, ainda é uma meta a alcançar. Principalmente no Brasil, onde não existe a profissão de cientista e em que a pesquisa é pouco valorizada.

Zeichner (2008) evidencia que deve haver uma revolução nas estruturas institucionais, nos currículos e nos conteúdos formativos, o que leva à compreensão de que é preciso repensar a estrutura dos cursos de formação inicial de professores. Também Nóvoa (1992) ressalta que a formação do professor pesquisador exige ofertar aos docentes condições de pensar e assumir a sua realidade escolar como um objeto de pesquisa e análise, constituindo um movimento dialético e contra-hegemônico frente ao movimento de desvalorização da profissão docente e da mera instrumentalização da sua prática. André e Pesce (2012, p. 4) ressaltam que

\begin{abstract}
A formação do professor pesquisador também pode ser vista como uma forma de ajudar a melhorar o ensino, possibilitando que o docente exerça, com os alunos, um trabalho que vise à formulação de novos conhecimentos, ou o questionamento tanto da validade quanto da pertinência dos já existentes. É essencial que o professor deixe de ser um técnico, reprodutor das práticas convencionais que são internalizadas pela força da tradição, e passe a ser autor de sua ação educativa.
\end{abstract}

Também Contreras (2012) defende que a formação do professor pesquisador representa uma possibilidade, nela o futuro docente poderá analisar sua prática, levando em consideração a relação existente entre seu fazer e as condições educacionais e sociais, o que pode ajudá-lo a desenvolver os saberes próprios da docência. Para Zeichner (1992), o professor deve sistematizar sua reflexão, tornando-a investigativa, realizando, em sala de aula, pesquisas que se voltem para solucionar problemas inerentes ao cotidiano da sala de aula, com o objetivo de melhorar o processo de ensino e aprendizagem. Assim, este profissional estará habilitado para dominar técnicas de pesquisa, como identificar o objeto de estudo, metodologias, realizar diagnósticos, levantar hipóteses e ou problemáticas, buscar fundamentação teórica, analisar dados e, por fim, propor soluções.

Apesar de existir uma consciência entre os estudiosos citados sobre a urgência da integração entre a pesquisa e o ensino, a formação inicial, muitas vezes, não forma os futuros docentes para compreender o mundo da pesquisa e agir com/sobre este mundo. Para ter acesso a conhecimentos específicos da pesquisa durante a graduação, é interessante a participação e o envolvimento dos discentes em programas de pesquisa e extensão universitária, tais como: Programa de Iniciação Cientifica (PIBIC), Projeto de 
Atividade Extensão Universitária (PACE), Projeto de Iniciação à Docência (PIBID) ou outros voltados à formação docente, como a Residência Pedagógica, programa do Governo Federal implantado recentemente nos cursos de licenciatura, ou mesmo preparar e incentivar os discentes a continuarem sua formação em nível de pós-graduação nos programas de mestrado e doutorado disponibilizados por grande parte de universidades brasileiras.

A escola sozinha já não dá conta de responder às necessidades de uma sociedade tecnológica que está ainda em processo de mudança. É imprescindível a formação, já na graduação, de profissionais docentes sejam bem preparados, de forma que consigam transformar o espaço escolar em um espaço de aprendizagem, dinâmico, formativo, diversificado, atraente e significativo. Apoiamo-nos em Dussel (2009, p. 375) para afirmar que a escola

[...] era um espaço de transmissão cultural cuja cultura se distinguia claramente do afora e se sustentava numa aliança entre o Estado e as famílias, na atualidade a escola compete com outras agências culturais como os meios de comunicação de massas e a internet para a transmissão de saberes, a formação intelectual e a educação da sensibilidade das crianças e adolescentes.

Por esses motivos que cita Dussel (2009), exige-se mais do professor e de sua formação inicial, inclusive para formar o professor pesquisador, já que a prática acadêmica e a pesquisa vêm representar um recurso significativo no desenvolvimento profissional do aluno/pesquisador, e o curso de graduação em Pedagogia do IEAA promove, através de eventos educacionais, práticas de estágios supervisionados, projetos de formação docente (PIBIC, PIBID, PACE, RE) e outros que fazem parte do contexto formativo de professores nas universidades.

Vale ressaltar que alguns acadêmicos do IEAA/UFAM têm se esforçado para a prática da pesquisa por meio de participações em projetos de extensão e outras práticas formativas. Mota (2017), em função da elaboração de seu Trabalho de Conclusão de Curso no âmbito do Curso de Pedagogia do IEAA/UFAM, realizou um levantamento a respeito das produções acadêmicas dos discentes do referido curso e verificou alguns resultados de pesquisa e relatos de experiência das participações em projetos de extensão, estágios supervisionados, PIBIC e PIBID. O autor mostra que houve divulgação acadêmico-científica de vários artigos e comunicações orais produzidos em decorrência de relatórios das atividades práticas desenvolvidas no âmbito da universidade durante a graduação, inclusive, parte das produções dos TCCs foi desencadeada em função das atividades de extensão e práticas pedagógicas e de pesquisas.

No levantamento citado, Mota (2017) mostra que, em junho de 2017, foram apresentados no Fórum Internacional sobre a Amazônia na Universidade Federal de Brasília (FIA/UNB) 10 artigos científicos - entre comunicação oral e pôster. Em setembro de 2017, no Seminário de Educação na Universidade Federal de Mato Grosso (SEMIEDU/UFMT) foram realizadas 4 comunicações orais. Em outubro do mesmo ano, na I Jornada do HISTEDBR/UNIR, foram 5 trabalhos acadêmicos. Também em outubro de 2017, na Associação Nacional de Política e Administração da Educação (ANPAE/AM), foram publicados 24 trabalhos. Ampliando o levantamento de Mota (2017), foi possível verificar que os estudantes do IEAA/UFAM publicaram, em 2018, entre resultados de pesquisa e relatos de experiência, mais de 15 trabalhos orais e pôsteres no I Seminário de Educação: sexualidade, gênero e educação e VI Semana de Pedagogia do IEAA e, em 2019, no primeiro semestre, foram apresentados no II Fórum Internacional sobre a Amazônia, 7 trabalhos, resultados de PIBIC e relato de experiência de Estágio Supervisionado.

Cabe mencionar que, tanto as produções mostradas no levantamento de Mota (2017) como aquelas que fazem parte da ampliação do estudo da autora são resultado de relatos de experiência de atividades curriculares de extensão universitária, estágios supervisionados PIBIC, PIBID e Monitoria acadêmica, além de recortes de pesquisas 
realizadas em disciplinas e TCCs. Esses são exemplos de que há, de certa forma, empenho na formação docente em formar os futuros professores para a pesquisa articulada à prática da extensão.

Porém, entende-se que ainda há muito que se fazer neste sentido, uma vez que a quantidade de alunos que participam de eventos com resultados de pesquisa ainda é minoria, levando-se em consideração o número de alunos matriculados nos cursos. No caso da UFAM, constatou-se, por exemplo, uma pequena participação dos acadêmicos em eventos internos no IEAA, sem grandes proporções de publicações (MOTA, 2017), o que leva a entender que os estudantes se interessam em publicar resultados de trabalhos em eventos externos à universidade de origem. "Nem sempre a responsabilidade pela pouca participação em pesquisa tem sido do curso, uma vez que há professores que divulgam, se colocam à disposição para orientação, mas que, em grande parte, são pouco procurados pelos discentes" (MOTA, 2017, p. 31).

O levantamento de Mota (2017) mostra que é possível formar o professor pesquisador levando-se em consideração a necessidade de atuação desse tipo de profissional nas escolas. A pesquisa é um recurso indispensável tanto sobre sua área específica como sobre sua prática pedagógica, as quais, na maior parte das vezes, estão integradas. Este profissional na educação traria melhoras significativas para a qualidade do ensino, exercendo mudanças essenciais na educação e formação dos sujeitos.

De acordo com André (2012), a formação do professor pesquisador pode ser uma das possibilidades de profissionalização da docência, pois através dela o professor pode ser capaz de refletir sobre sua prática profissional e de buscar formas (conhecimentos, habilidades, atitudes, relações) que o ajudem a aperfeiçoar cada vez mais seu trabalho docente, de modo que possa participar efetivamente do processo de emancipação das pessoas. Ao utilizar as ferramentas que lhe possibilitem uma leitura crítica da prática docente, há a identificação de caminhos para a superação de suas dificuldades.

Segundo Gatti (2010), as propostas curriculares dos cursos de licenciatura não demonstram avanços e não favorecem sólidos conhecimentos teórico-práticos para juntar pesquisa, ensino e extensão. É necessário haver mudanças significativas nos currículos dos cursos de graduação, nos conteúdos formativos e na estrutura dos cursos, a fím de superar a distância entre o tripé universitário (ensino, pesquisa e extensão) durante a formação inicial dos professores. Mudança que não ocorre com tanta facilidade, já que existe aí uma série de interesses de grupos e classes sociais particulares que primam pela centralização do ensino universitário, o que pode comprometer ainda o processo.

Consideramos importante suscitar o debate sobre a formação do professor pesquisador ainda na graduação, ressaltar a importância das práticas de pesquisa para a formação pessoal do sujeito e os benefícios que a presença desse profissional numa sala de aula da educação básica traria para a qualidade do ensino e da formação dos alunos. No entanto, é possível perceber que as possibilidades de formar esse tipo de profissional ainda na graduação estão cada vez mais dificultadas, considerando que as estruturas curriculares e culturais dos cursos de formação inicial não dão conta de formá-lo, além de as políticas do governo atual irem na contramão dos investimentos na educação superior pública.

É necessário evidenciar os desafios existentes no processo de formação inicial do profissional docente, para assim se poder explicitar os benefícios do conhecimento sobre o ato de pesquisar, despertar o interesse dos estudantes da graduação pela pesquisa e por seus benefícios na atuação como docente. Este desafio está posto e precisa ser superado se quisermos fazer a diferença em nossas salas de aula e alterar minimamente a estrutura da organização escolar, ultrapassada em algumas facetas e que precisa ser repensada. 


\section{Extensão universitária como elemento de formação consistente: o que mostram os relatos de experiência dos discentes?}

Considerando a necessidade de adensar as discussões estabelecidas, pensamos ser oportuno expor parte de dados produzidos em 2018 a partir da realização de experiências em Programas de Atividade Curricular de Extensão -PACE na UFAM. Foi realizado um conjunto de ações a partir de encontros semanais em uma escola pública no município de Humaitá AM, onde buscou-se atender 48 crianças de idades entre 3 a 11 anos, divididas em grupos de trabalhos. Os trabalhos foram realizados no período de agosto a dezembro de 2018. O referido projeto foi intitulado Registrando emoções: A literatura infanto juvenil como contributo para a promoção humana no contexto municipal de Humaitá/AM e objetivou interligar ações desenvolvidas entre a Universidade Federal do Amazonas - IEAA e profissionais da saúde de Humaitá/AM, no sentido de possibilitar às crianças que vivem em situação de vulnerabilidade a oportunidade de vivenciarem espaços de leitura e contação de histórias como possibilidade de expressarem sentimentos, angústias e emoções, por meio de registros orais, escritos e/ou ilustrações, vivenciados em meios às ocorrências cotidianas (ALVES, 2018).

Acreditamos ser relevante apresentar brevemente o lugar de onde foram efetivadas as experiências. A cidade de Humaitá/AM está localizada no sul do estado do Amazonas, próxima à fronteira norte do estado de Rondônia. Segundo dados do IBGE (2018), o município possui uma população de 54 mil habitantes, conta com uma população escolar de 9.094 estudantes matriculados no ensino fundamental e 2.468 estudantes no ensino médio. Trata-se de uma cidade com grande desigualdade social e uma ampla população em situação de vulnerabilidade social, o que torna a extensão um projeto necessário e urgente no âmbito dos cursos de formação.

O Projeto visou melhorar o rendimento escolar por meio da literatura infantojuvenil, no sentido de diminuir os índices de reprovação de crianças que se encontram em desnível idade/série, intencionado proporcionar-lhes maior rendimento escolar. As atividades foram desenvolvidas sob a forma de contação de história, leitura, desenho (ilustração) e resumo escrito. Como exposto no texto, a abordagem metodológica na aplicação da extensão mencionada foi qualitativa, com ênfase em uma práxis educativa, um movimento de ação-reflexão-ação, em que houve intervenção pedagógica por parte da Universidade na atividade curricular de extensão.

Ao final do projeto de extensão, as crianças mostraram avanço nos processos de leitura e escrita, bem como no uso da oralidade e consequentes expressões emotivas, além de melhorias no processo de interpretação de leituras, relacionando-as às suas vivências cotidianas (ALVES, 2018).

Participaram do programa de extensão 19 estudantes, sendo 18 discentes do Curso de Pedagogia e uma do Curso de Letras, além de uma psicóloga e uma enfermeira da rede pública de saúde de Humaitá/AM, e colaboradores internos e externos (uma professora do IEAA/UFAM e um professor da UNIR/RO).

Dos 19 relatos experiência, selecionamos 11 relatos para análise por considerarmos grande o número de documentos a serem sistematizados. E importante mencionar que os discentes dos quais analisamos os relatos de experiência não serão identificados, visando garantir o seu anonimato. Assim, reportarmo-nos a eles a partir de um código criado de forma aleatória, sendo R1, R2, R3, como Relato 1, Relato 2, Relato 3, e assim por diante. Os depoimentos aqui postos são recorte dos relatos de experiência dos discentes que participaram do projeto. Os relatos fazem parte da avaliação final da atividade de extensão realizada, exigência da Pró-Reitoria de Extensão e Interiorização da Universidade Federal do Amazonas - PROEXTI 1 /UFAM e encontram-se disponíveis nos arquivos do projeto.

Sobre a relação teoria e prática, podemos inferir, a partir dos relatos dos discentes, que as atividades curriculares de extensão têm sido relevantes no processo de formação docente. Trechos dos depoimentos possibilitam inferir a aproximação entre a extensão e a prática formativa reflexiva: 
R1 - O projeto foi importante para a comunidade, percebi que muitas crianças puderam ter o contato com a leitura e a escrita, além de expressarem suas emocões provocadas pelas histórias lidas em suas ilustracões. Estas atividades de extensão servirão de auxílio mim, futura pedagoga, no exercício de minha profissão docente. As atividades trabalhadas foram no sentido de orientar e estimular o processo formativo dos discentes, auxiliando-nos no contato entre a teoria e a prática. Considero o projeto de grande importância para minha vida como futura profissional da educacão, pois tive contato com a teoria e a prática, pois sabemos que esses dois processos devem caminhar juntos para o bom rendimento e aprendizagem. $\mathrm{R} 2$ - O projeto nos proporcionou uma experiência única, pois através do contato com as crianças também foi possivel aprender, houve uma troca muito importante ao ensinar e aprender.

R3 - Os ensinamentos e aprendizagens que obtive durante o projeto muito importante para minha formação.

R4 - Os conhecimentos adquiridos ao longo das atividades possibilitou uma gama de conhecimentos no processo de formação pessoal e acadêmica.

R5 - Ganhei experiências de suma importância para meu desenvolvimento formativo na UFAM, entre elas, a oportunidade de estar em sala de aula com alunos, algo que até então não tinha acontecido, o prazer de ver os olhos das crianças brilhando ao descobrir histórias diferentes é algo impagável. Atuei como professora ao mesmo tempo em que era aluna.

R6 - O projeto de extensão foi uma grande oportunidade para desenvolver o conhecimento e colocá-lo em prática.

R7 - Ganhei experiência, foi de extrema importância para a minha formação docente, tive a oportunidade de estar em sala de aula desenvolvendo saberes antes nunca trabalhado. Percebi a relação teoria e prática.

R8 - Aos discentes, o projeto contribui em sua formação acadêmica, proporcionando a construção da prática no processo de ensino e aprendizagem.

R9 - Tivemos encontros positivos. É gratificante poder ensinar e aprender, tive experiências que serão de suma importância para meu futuro como educadora.

R10 - Foi por meio do projeto que vivenciei as primeiras experiências da sala de aula, levarei para minha carreira profissional.

R11 - As experiências alcançadas no decorrer do projeto foram de suma importância para minha formação acadêmica para a docência.

R12 - Para nós, professores em formação, fazer esta experiência foi muito significativo. Tivemos a oportunidade de associar a teoria que estudamos na universidade com a realidade em que se dá a educação.

Os relatos mostram que as ações voltadas para relação teoria e prática contribuem na formação do graduando na medida em que propiciam atividades ricas em experiência, como: realização de oficinas, elaboração de planejamento e atividades que possibilitam superar as dificuldades de leitura e de escrita; planejamento da ação prática, avaliação das ações desenvolvidas e reuniões periódicas para a discussão de entraves e/ou sucesso detectados nas ações planejadas.

Tudo isso são desafios que servem para enriquecer a formação do graduando, uma vez que tais ações fornecem um conjunto de saberes que poderão levar o discente a uma profissionalização mais qualificada. Neste sentido,

\begin{abstract}
A extensão universitária, entre a diversidade de entendimentos, pode ser considerada uma diretriz institucional, um processo mediador de construção do conhecimento e uma atividade que aponta para a finalidade do percurso da aprendizagem, qualificando o valor epistemológico, ético e político da instituição, que deve ser vivenciado, cotidianamente, pelos sujeitos acadêmicos e comunitários, pelos processos instituídos e instituintes, e pelos resultados individuais e coletivos (COSTA-RENDERS, 2013, p. 20).
\end{abstract}

Desta forma, entendemos que a experiência e a reflexão sobre a prática aparecem nos relatos dos discentes e permitem a compreensão de que a relação teoria e prática é essencial na formação docente. É importante destacar que o Projeto de Atividades Curriculares de Extensão (PACE/UFAM) oportuniza experiências formativas, e, como enfatiza Tardif (2000), os cursos de formação docente devem ser voltados para a ação e reflexão do conhecimento, sendo que, nos primeiros anos da formação, os conteúdos devem ser constituídos de "conhecimentos proposicionais" (TARDIF, 2000, p.18), possibilitando a relação teoria e prática. 
Também apoiamos-nos em Nóvoa (1997) para afirmar que a formação docente

[...] não se constrói por acumulação (de cursos, de conhecimentos, ou de técnicas), mas sim através de um trabalho de reflexividade crítica sobre as práticas e de (re) construção permanente de uma identidade pessoal. Por isso é tã̃o importante investir a pessoa e dar estatuto ao saber da experiência (NÓVOA, 1997, p. 25).

Cabe destacar que a formação de professores, devido à rigidez curricular e metodológica dos cursos de formação, muitas vezes promove a falta de articulação da teoria com a prática ou a quantidade excessiva de teorias e pouca prática. De acordo com Formosinho (2009, p. 83), "um componente importante da formação do futuro professor consiste na prática docente dos seus formadores no curso de formação inicial". Para o autor, a própria prática do professor que está formando um futuro professor diz muito sobre o professor que será formado.

O professor tem a formação inicial que ocorre durante o processo da academia, deparando-se com teorias e conhecimentos que serão utilizados por ele no processo da sua prática cotidiana no ambiente escolar. Esta formação inicial de professores é de suma importância para a definição do que um profissional da educação precisa saber e compreender para atuar em meio educacional, porém, a formação de um professor não se limita somente nesse processo inicial.

Para Tardif (2002, p. 39), "professor ideal é alguém que deve conhecer sua matéria, sua disciplina e seu programa, além de possuir certos conhecimentos relativos às ciências da educação e à pedagogia e desenvolver um saber prático baseado em sua experiência cotidiana com os alunos".

Sobre a formação docente, Day (2001) afirma que

Os professores constituem o maior trunfo da escola estão na interface entre a transmissão do conhecimento, das destrezas e dos valores. Todavia, os professores só poderão realizar os objetivos educacionais se tiverem uma formação adequada e, ao mesmo tempo, se forem capazes de garantir e melhorar o seu contributo profissional através do empenhamento numa aprendizagem ao longo de toda carreira (DAY, 2001, p. 16).

Também Nóvoa (2002, p. 23) vem afirmar que: “O aprender contínuo é essencial, se concentra em dois pilares: a própria pessoa, como agente, e a escola, como lugar de crescimento profissional permanente." Para o autor, a formação continuada se dá de maneira coletiva e depende da experiência e da reflexão como instrumentos contínuos de análise, e, deste modo, uma formação bem estruturada e contínua é indispensável para uma boa prática docente.

\section{Considerações finais}

As atividades desenvolvidas no projeto possibilitaram a compreensão sobre a importância da leitura como contributo na promoção humana. Percebeu-se que muitas crianças possuem dificuldade em leitura, porém, pelo relato das famílias e das próprias crianças, estas passaram a ter mais interesse pela leitura, trazendo para as discussões situações cotidianas, as histórias vividas relacionadas às histórias lidas nos dias do PACE. Foram desenvolvidas atividades de leitura que contemplassem o desenvolvimento da oralidade, da escrita e da interpretação, além da capacidade de expressão por meio do desenho ilustrativo.

Os resultados foram sistematizados e organizados em um livro de resumo (disponibilizado nos arquivos pessoais da coordenadora da extensão) e produção de 
camisetas trabalhadas em serigrafia com giz de cera, que, ao final do PACE, foram entregues às crianças e/ou familiares. Com relação ao material didático do projeto, a escolha deles facilitou o desenvolvimento pedagógico das atividades propostas. Procuramos fazer com que os alunos compartilhassem suas interpretações sobre leitura da história lida, com o intuito de fazer com que eles viessem a perder a timidez e o constrangimento de falar em público.

Os resultados são considerados positivos por oportunizar a vivência com a leitura de diferentes formas, bem como a possibilidade de os acadêmicos envolvidos relacionarem teoria e prática. Ainda, tanto para as crianças que, por meio das atividades, conseguiram se desenvolver no processo de desenvolvimento da língua escrita, da oralidade e da expressão por meio do desenho, como para os acadêmicos participantes do projeto, que puderam relacionar teoria e prática no contexto de formação docente. Vale ressaltar que todas as atividades realizadas com as crianças neste projeto de PACE estiveram de acordo com as dificuldades apresentadas de forma individual, de maneira que garantíssemos a autonomia e a subjetividade de cada criança e em consonância com cada grupo etário.

Diante do exposto, consideramos a extensão universitária como um elemento formador ativo, capaz de proporcionar a relação teoria e prática e mostrar possibilidades de pesquisa acadêmica na formação inicial docente.

\section{Referências}

ALVES, Maria Isabel Alonso. Registrando emoções: A literatura infanto juvenil como contributo para a promoção humana no contexto municipal de Humaitá/AM. Relatório Final da Atividade Curricular de Extensão. PROEXTI. Universidade Federal do Amazonas - UFAM, 2018.

ANDRÉ, Marli. O papel mediador da pesquisa no ensino da didática. In: ANDRÉ, M.; OLIVEIRA, M. R. (Orgs.). Alternativas do ensino da didática. Campinas/SP: Papirus, 1997. p. 19-36.

ANDRÉ, Marli; PESCE, Marly Krunger. Formação do professor pesquisador na visão do professor formador,. v., n. 7, jul.-dez. 2012.

ANDRE, Marli. Políticas e programas de apoio aos professores iniciantes no Brasil. Cad. Pesqui., 2012, v.42, n.145, p.112-129.

CONTRERAS, José. A autonomia de professores. São Paulo: Cortez, 2002.

COSTA-RENDERS, Elizabete Cristina; SILVA, Luciane Duarte da. A extensão e o alargamento do espaço de ensino-aprendizagem na educação superior. In: SÍVERES, Luiz (Org.). A Extensão universitária como um princípio de aprendizagem. Brasília: Liber Livro, 2013.

DAY, Christopher. Desenvolvimento Profissional de Professores: os desafios da aprendizagem permanente. Porto: Porto Editora, 2001.

DUSSEL, Inés. A transmissão cultural assediada: metamorfoses da cultura comum na escola. Caderno de Pesquisa, São Paulo, v.39, n. 137, maio/ago. 2009, p. 351-365. 
FREIRE, Paulo. Pedagogia do oprimido. Rio de Janeiro: Paz e Terra, 2008.

GATTI, Bernadete. Formação de professores no Brasil: características e problemas.

Educ. Soc., Campinas, v. 31, n. 113, p. 1355-1379, out.-dez. 2010.

GODOY, Arilda Schmidt. Pesquisa qualitativa tipos fundamentais. Revista de Administração de Empresas, São Paulo, v. 35, n.3, p. 20-29, maio.-jun. 1995.

GONSALVES, Elisa Pereira. Conversas sobre á pesquisa cientifica. 4.ed Campinas, SP: Alínea, 2007.

LUDKE, Menga; ANDRÉ, Marli. Pesquisa em educação: Abordagem qualitativa. 2. ed. Rio de Janeiro: EPU, 2013.

MOTA, Fabiane. Um "bicho papão" chamado TCC: o que dizem os egressos do curso de pedagogia do IEAA. Monografia (Graduação em Pedagogia) Instituto de Educação, Agricultura e Ambiente/ Universidade Federal do Amazonas - IEAA/UFAM, Humaitá, AM, 2017.

NÓVOA, A. Formação de professores e profissão docente. In: NÓVOA, A. (Org.). Os Professores e sua formação. Lisboa: Dom Quixote, 1992.

TARDIF, Maurice. Saberes profissionais dos professores e conhecimentos universitários. Elementos para uma epistemologia da prática profissional dos professores e suas conseqüências em relação à formação para o magistério. Revista Brasileira de Educação, n.13, 2000.

PIO, Paulo Martins; CARVALHO, Sandra Maria Gadelha de; MENDES, José Ernandi. Práxis e prática educativa em Paulo Freire: reflexões para a formação e a docência. EdUECE- Livro 2, 2014.

TARDIF, Maurice. Saberes docentes e formação profissional. Petrópolis: Vozes, 2002.

ZEICHNER, K. Novos caminhos para o practicum: uma perspectiva para os anos 90. In: NÓVOA, A. (Org.). Os Professores e sua formação. Lisboa: Dom Quixote, 1992.

ZEICHNER, Kenneth M. Uma análise crítica sobre a "reflexão" como conceito estruturante na formação docente. Educ. Soc., v.29, n.103, 2008.

\section{Notas}

${ }^{1} \mathrm{O}$ site da PROEXTI/UFAM pode ser acessado no endereço: www.proexti.ufam.edu.br 